\title{
Synthesis of Hierarchical-Structured Zn/Mo-HZSM-5 and Its Application in Dimethy Ether Aromatization
}

\author{
Yali Lu, Donglin Wang, Yibing Song, Qiuli Yang, Meili Fu, Daoke Yu, YiWen Fang \\ Department of Chemistry \\ Shantou University \\ Guangzhou, 810008, China \\ e-mail: 12yllu@stu.edu.cn
}

\begin{abstract}
The hierarchical-structured Zn/Mo-HZSM-5 catalyst was synthesized by two-step crystallization and impregnation method, and characterized by XRD, HRTEM and $\mathrm{N}_{2}$ adsorption-desorption. The results indicates that the obtained catalyst has a large specific surface area and pore volume. The catalyst exhibits good activity and stability in DME aromatization. The selectivity of aromatics reaches $84.5 \%$ at $420^{\circ} \mathrm{C}$. When the reaction time reaches $160 \mathrm{~h}$, the total aromatics selectivity remain at $\mathbf{7 1 . 2 \%}$.
\end{abstract}

Keywords-hierarchical-structured; Zn/Mo-HZSM-5; DME; aromatization.

\section{INTRODUCTION}

Benzene, toluene and xylene are called BTX, an important chemical raw material, and mainly derived from oil, widely used in synthetic fiber, resin, rubber, detergent and dye, medicine and other fields. At present, the BTX is derived from catalytic reforming process, pyrolysis gasoline and coal tar separation. However, shortage of raw materials, complex process, the selectivity is difficult to improve, so researching new process of producing BTX and other light aromatics, has very important theoretical and practical significance.

Today, with the rapid development of domestic coal chemical industry, the coal-to-DME production scale expanding unceasingly, it is important significance to the development of downstream products ${ }^{[1]}$. DME transformation mainly include hydroxylation, selective oxidation, oxidation coupling and reforming hydrogen and dehydration to olefin etc. ${ }^{[2]}$. DME has been converted to aromatic hydrocarbons, but the related research is less at home and abroad. Kecskemti first reported the study of DME aromatic hydrocarbons, the aromatics selectivity over $\mathrm{Mo}_{2} \mathrm{C} / \mathrm{ZSM}-5\left(5 \% \mathrm{Mo}_{2} \mathrm{C}\right)$ catalyst at $500^{\circ} \mathrm{C}$ was $60.8 \%{ }^{[3]}$. ZSM-5 as catalyst with strong acid, high aromatic hydrocarbon selectivity, but the low stability of catalyst hindered its industrialization ${ }^{[4,5]}$. The study of catalyst for DME aromatization is focused on how to control the catalyst particle size, pore structure and acid amount, as well as the development of new catalyst materials $^{[6]}$.

In this paper, hierarchical-structured $\mathrm{Zn} / \mathrm{Mo}-\mathrm{HZSM}-5$ zeolite has been synthesized by using mesoporous and microporous template agent. The structure and morphology of sample were characterized, and the catalytic performance was investigated in the DME aromatization.

\section{EXPERIMENTAL}

\section{A. Preparation of Materials and Catalysts}

The hierarchical-structured catalyst Zn/HMoZSM-5 $(\mathrm{Si} / \mathrm{Al}=80)$ was synthesized by two-step crystallization. In synthesis procedure, the precursor ZSM-5 was prepared by mixing $\mathrm{H}_{2} \mathrm{O}$ (deionized water), $13 \mathrm{ml}$ tetrapropylammonium hydroxide (TPAOH), $23 \mathrm{ml}$ tetraethyl orthosilicate (TEOS) and $0.26 \mathrm{~g}$ aluminium isopropoxide while being continuously stirred for $24 \mathrm{~h}$. The mixture was then transferred to an autoclave and heated to $100^{\circ} \mathrm{C}$ for $4 \mathrm{~h}$. After cooling to room temperature, the resulting suspension was added with $\mathrm{H}_{2} \mathrm{O}$ and $4.37 \mathrm{~g}$ cetyltrimethyl ammoniumbromide (CTAB) solution containing $2 \mathrm{~g} \mathrm{NaOH}$ and $\mathrm{Mo}$ to obtain a final gel. The gel was continuously stirred for $2 \mathrm{~h}$ at room temperature, then transferred to an autoclave and heated $170^{\circ} \mathrm{C}$ for $8 \mathrm{~h}$. The reaction product was filtered, washed, dried at $110^{\circ} \mathrm{C}$ for $12 \mathrm{~h}$ and calcined at $550^{\circ} \mathrm{C}$ for $6 \mathrm{~h}$ to obtain hierarchical-structured Mo-ZSM-5. Hierarchical-structured Mo-ZSM-5 was Carried on 3 times ion-exchange with a $0.1 \mathrm{~mol} / \mathrm{L} \mathrm{NH}_{4} \mathrm{NO}_{3}$ solution at $75^{\circ} \mathrm{C}$ for $2 \mathrm{~h}$, followed by calcination. Then $\mathrm{Zn}$ was loaded on the hierarchical-structured Mo-HZSM-5 zeolite by impregnation to form hierarchical-structured Zn/Mo-HZSM-5 catalyst.

\section{B. Characterization methods}

X-ray diffraction (XRD) patterns were recorded using Bruke/D8 Powder X-ray diffractometer with $\mathrm{Cu}-\mathrm{K} \alpha$ radiation. High resolution transmission electron microscopy (HRTEM) images were recorded using a JEM 2100 microscope with an accelerating voltage of $200 \mathrm{kV}$. $\mathrm{N}_{2}$ adsorption-desorption isotherms were measured using an ASAP 2020 system after the sample was degassed under vacuum at $300^{\circ} \mathrm{C}$ for $3 \mathrm{~h}$. Pore size distribution was determined using the conventional Barrett-Joyner-Halenda (BJH) model.

\section{DME aromatization reaction test}

The DME aromatization reaction, under anaerobic conditions, was conducted in a fixed bed reactor operating at $0.1 \mathrm{MPa}$. The cylindrical fixed bed reactor was made of 
stainless steel, packed with $0.3 \mathrm{~g}$ (size of 40-60 mesh) catalyst. Under $\mathrm{N}_{2}$ atmosphere, heated to reaction temperature at a rate of $20 \mathrm{~K} / \mathrm{min}$, and keeping $0.5 \mathrm{~h}$ to activate catalyst at reaction temperature. The DME $(3 \mathrm{ml} / \mathrm{min})$ and the dilution gas $\mathrm{N}_{2}(15 \mathrm{ml} / \mathrm{min})$ were passed into the reactor, the product was analyzed on-line using a GC9790 type gas chromatograph. Separation analysis conditions: Porapak-p packed column $(3 \mathrm{~m})$, column temperature $200^{\circ} \mathrm{C}$, gasification temperature $220^{\circ} \mathrm{C}$, flame ionization detector (FID), the carrier gas (He), detector temperature $250^{\circ} \mathrm{C}$, the $150 \mathrm{~mA}$ current condition.

\section{RESULT AND DISCUSSION}

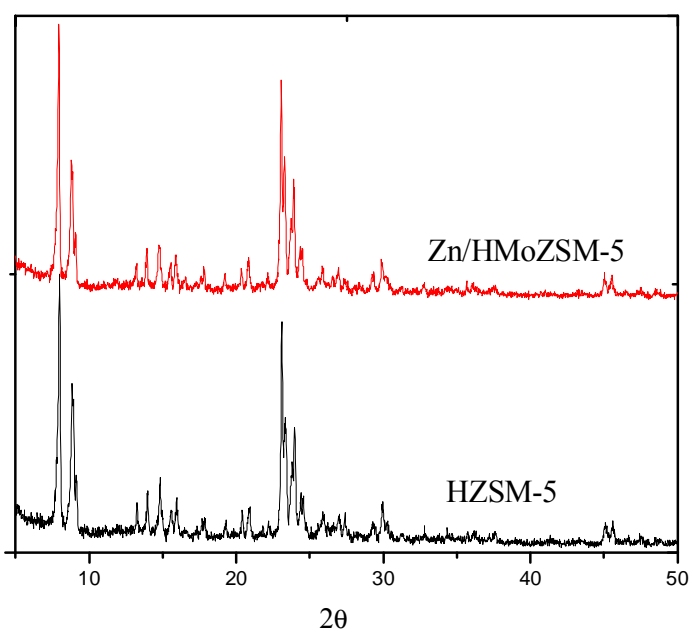

Fig. 1: XRD patterns of Zn/Mo-HZSM-5 and HZSM-5

Fig. 1 shows the XRD patterns of the Zn/Mo-HZSM-5 and standard HZSM-5. Zn/Mo-HZSM-5 has the sharp peaks in the ranges of $5^{\circ} \sim 40^{\circ}$, similar to the standard ZSM-5. The XRD peaks of $\mathrm{Zn} / \mathrm{Mo}-\mathrm{HZSM}-5$ is still clearly observable. There is no any peaks of Mo and $\mathrm{Zn}$ in the ranges of $30^{\circ} \sim 80^{\circ}$, it indicates that $\mathrm{Mo}$ and $\mathrm{Zn}$ dispersed evenly.

Fig. 2 shows the HRTEM images of Zn/Mo-HZSM-5. Fig. $2 \mathrm{a}$ shows that the Zn/Mo-HZSM-5 appears large cylindrical particles at $300-350 \mathrm{~nm}$ in sizes, and particle size distribution is uniform. There are a small amount of mixed crystal around the zeolite, due to the parts of material are not crystallized completely in solution. Fig. $2 b$ shows the zeolite appears pore with different sizes.
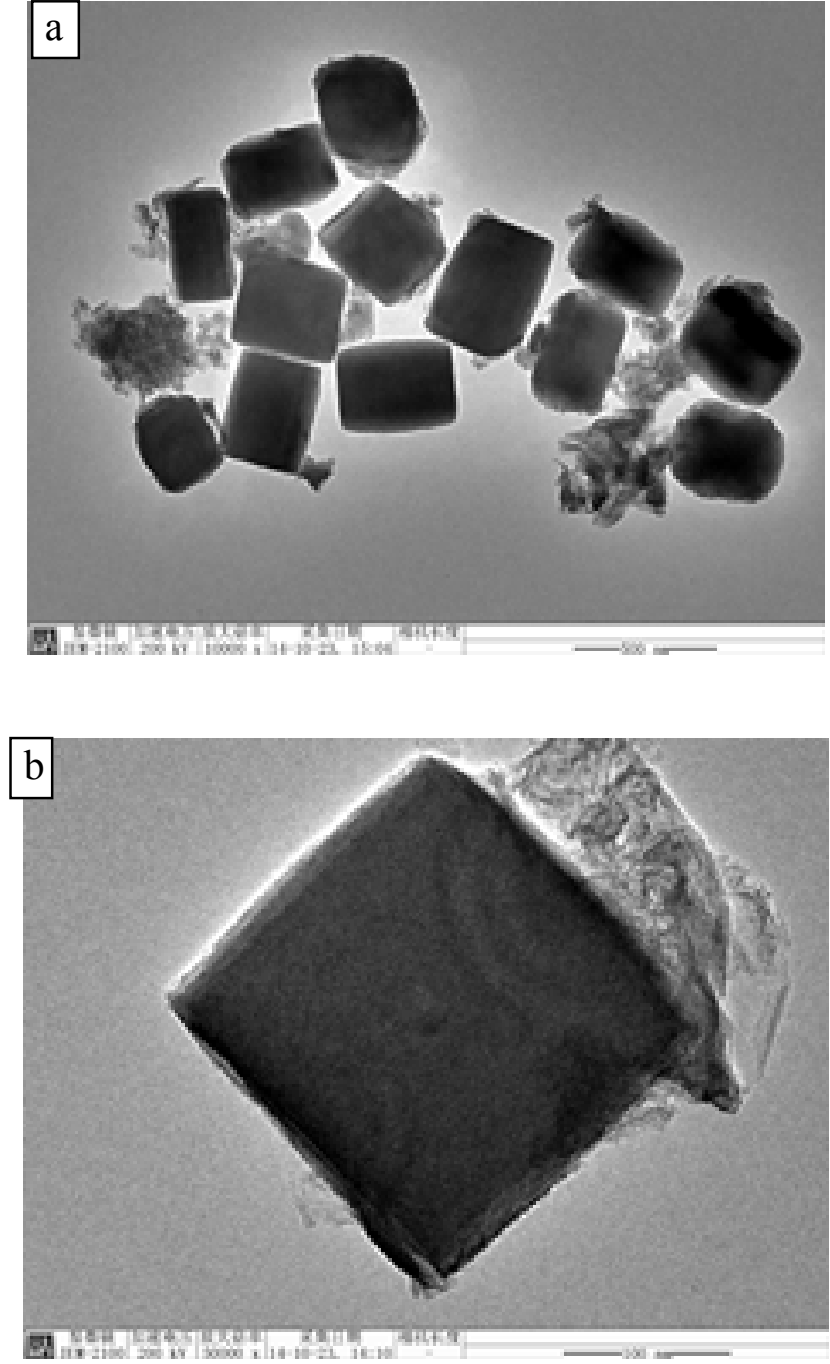

Fig.2: HRTEM images of Zn/Mo-HZSM-5

Fig.3 shows the $\mathrm{N}_{2}$ sorption isotherm and pore diameter distributions of the Zn/Mo-HZSM-5. It can be seen that the zeolite exhibits a typical irreversible type IV adsorption and desorption isothermal, which is characteristic of mesoporous molecular sieves ${ }^{[7,8]}$. The pore size distribution reveals that there are two type pores in the zeolite centered at $3.8 \mathrm{~nm}$ and $35.9 \mathrm{~nm}$ by the BJH method. 


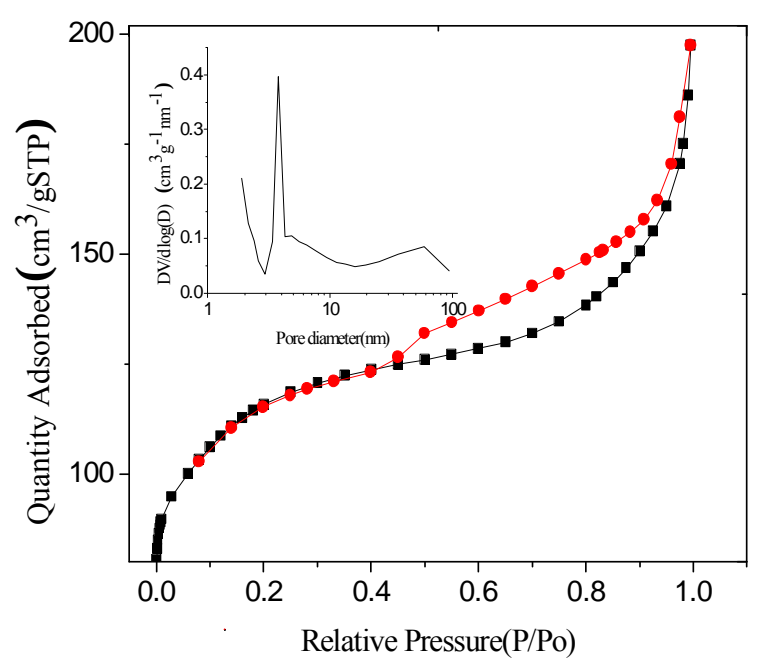

Fig.3: $\mathrm{N}_{2}$ sorption isotherm and pore diameter distributions of the Zn/Mo-HZSM-5

Fig.4 describes the influence of reaction temperature on the aromatization of DME over hierarchical H-ZSM-5 and $\mathrm{Zn} / \mathrm{Mo}-\mathrm{HZSM}-5$. As can be seen, DME aromatization already occurred at the condition of $180^{\circ} \mathrm{C}$, which indicates that hierarchical H-ZSM-5 and Zn/Mo-HZSM-5 both have high activity for DME aromatization. Moreover, the aromatization activity of $\mathrm{Zn} / \mathrm{Mo}-\mathrm{HZSM}-5$ is obviously higher than that of H-ZSM-5, it suggests that the metal centers of $\mathrm{Zn} / \mathrm{Mo}-\mathrm{HZSM}-5$ play an important role in the reaction. As the reaction temperature increase, the selectivity of aromatics increase rapidly, and leveled off after $420^{\circ} \mathrm{C}$. This suggests that higher reaction temperatures benefit to aromatization reaction ${ }^{[9]}$.

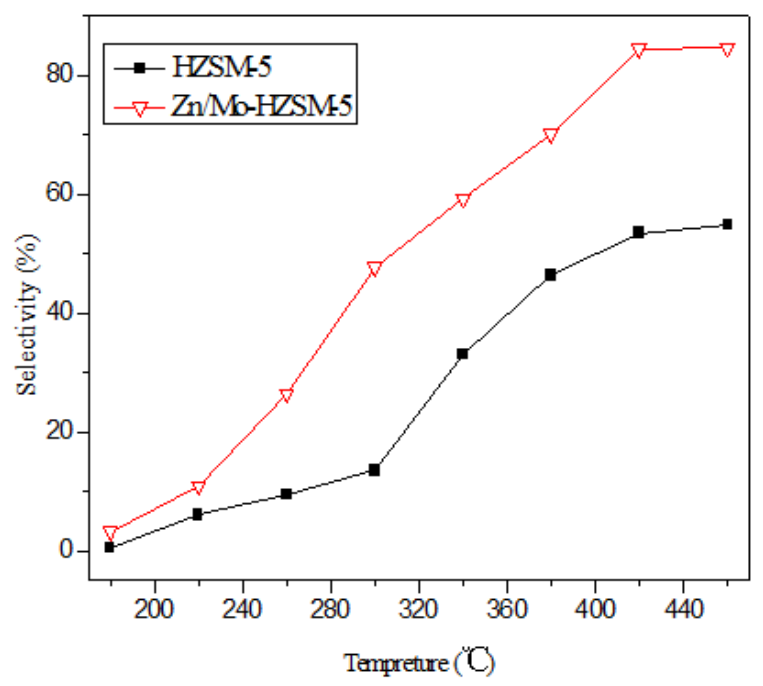

Fig.4: Effect of reaction temperature on performance in the aromatization of DME over hierarchical HZSM-5 and Zn/Mo-HZSM-5

The activity and stability of Zn/Mo-HZSM-5 zeolite were researched in DME aromatization at the optimal reaction condition (conversion rate 100\%). Fig.5 shows the aromatics selectivity over all samples. The Zn/Mo-HZSM-5 catalyst exhibits good activity and stability in DME aromatization. The aromatics selectivity decrease with reaction time, but the total aromatics selectivity remain at $71.2 \%$ when the reaction time reaches $160 \mathrm{~h}$. Comparing with the traditional ZSM-5 zeolite, the existence of the hierarchical structural pore, make it easier for the product spreading out from the channel, carbon deposit produced difficultly, thus the stability of Zn/Mo-HZSM-5 increases significantly.

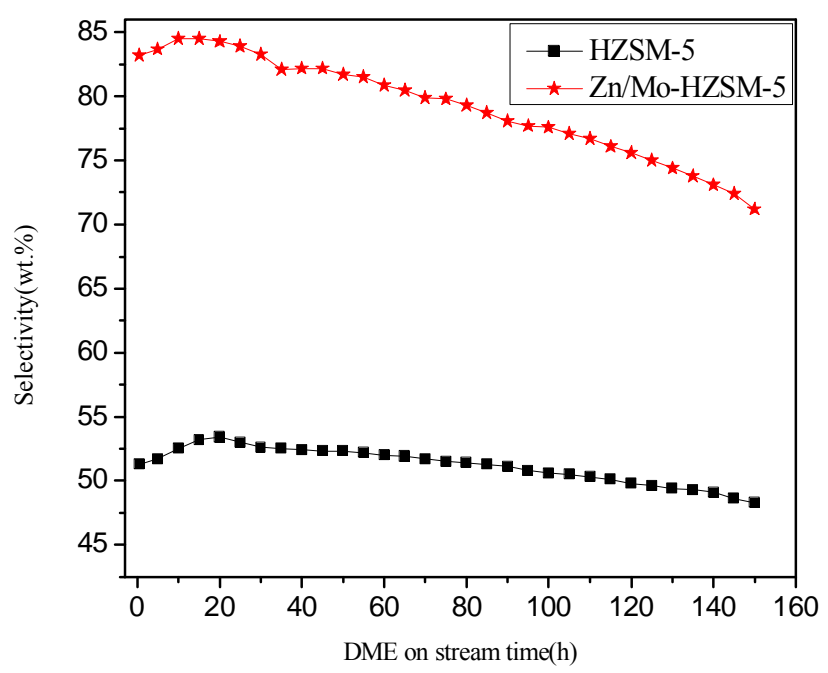

Fig.5: The activity and stability testing of zeolites

\section{CONCLUSION}

Given the above observations, hierarchical-structured Zn/Mo-HZSM-5 zeolite was synthesized by two-step crystallization. The morphology of sample is almost unaffected after Mo and $\mathrm{Zn}$ modified; The aromatics selectivity for DME aromatization over $\mathrm{Zn} / \mathrm{Mo}-\mathrm{HZSM}-5$ reaches $85 \%$ at $420^{\circ} \mathrm{C}$. Compared with the traditional ZSM-5, the stability of Zn/HMoZSM-5 zeolite increases significantly, which is due to the existence of mesoporous structure.

\section{ACKNOWLEDGMENTS}

This work was financially supported by the Subject and specialty construction special fund of Guangdong Provincial Higher Education Institution (No. 2012CXZD0024, No. 2013KJCX0081).

\section{REFERENCES}

[1] Sh L Yan. China Petrol Chem Ind (In Chinese), 2008, (13): 28.

[2] M Sun, L Yu, Ch Y Sun, Y B Song, J Sun. Fine Chem, 2003, 20: 695.

[3] A.Kecskemeti, R.Barthos, F.Solymosi. Aromatization of dimethyl and diethyl ethers on Mo2C-promoted ZSM-5 catalysts. J Catal, 2008(258): 111-120.

[4] L P Xu Ren, B Li, J W Teng, The method of Methanol or dimethyl ether conversion propylene and aromatics (In Chinese), Google Patents, 2013. 
[5] Wei F Qian, X P Tang, X F Huang, W Yang.A method of methanol or dimethyl ether into ethylene propylene range of xylene (In Chinese), Google Patents, 2013.

[6] W Z Qian, X P Tang, F Wei, Synthesisof the catalyst of methanol and/or DME into aromatics and its application (In Chinese), Google Patents, 2013.
[7] Donohue MD, Aranovich GL. Adv Colloid Interface Sci 1998;76-77:139.

[8] Donohue MD, Aranovich GL. Fluid Phase Equilib 1999;561:158-60.

[9] Isagulyants G V, Gitis K M, Kondratev D A, Minachev Kh M. Stud Surf Sci Catal, 1984, 18: 225. 